\title{
THE RURAL MEDICAL PRACTITIONER OF INDIA
}

\author{
Udaragudi Prasada Rao', Nallapu Samson Sanjeeva Rao ${ }^{2}$
}

${ }_{1}^{1}$ Senior Resident, Department of Community Medicine, Guntur Medical College, Guntur, Andhra Pradesh

${ }^{2}$ Professor, Department of Community Medicine, NRI Medical College, Chinakakani, Mangalagiri Mandal, Guntur, Andhra Pradesh.

\section{ABSTRACT}

An unqualified healthcare practitioner without any formal registration practicing allopathic medicine can be called an RMP. Widely identified as a rural medical practitioner, the RMP in India enjoys much standing among rural residents and people living in urban slums. This group of self-styled practitioners, despite their lack of knowledge, skills and qualification are doing good business by taking advantage of the lacunae in the public health care system. One common excuse given is that as there is no qualified doctor, people have no choice but to use the services of these itinerant quacks. In earlier times, they indulged in medical practice of a limited nature. However, today their role has widened to that of a tout for city based doctors giving rise to a new system called RMP practice. The nexus between pharmaceutical companies and quacks is a much worse arrangement where numerous fledgling pharmaceutical companies support quacks, because they are a cheap source of marketing to unfortunate patients. The solution may rest in the establishment of proper round the clock hospitals in rural areas making basic health care of an acceptable degree available to the people. RMP practice must be condemned by all. If mainstreaming the RMP is considered, severe limitations as to invasiveness and hazards of drugs and procedures must be set with an emphasis on first aid and prompt referral. A better alternative is to educate people and empower them to promote their own health and prevent disease by following healthy lifestyles.

\section{KEYWORDS}

RMP, Quacks, RMP Practice, Qualification, Rural Health Provider.

HOW TO CITE THIS ARTICLE: Rao UP, Rao NSS. The rural medical practitioner of India. J. Evolution Med. Dent. Sci. 2017;6(74): 5321-5323, DOI: $10.14260 /$ Jemds/2017/1154

\section{BACKGROUND}

There is in India an entity called the RMP. The full form of the abbreviation is not clear. Many lay people believe that it stands for Registered Medical Practitioner, which is however very erroneous. Only the MBBS graduate is registered by the Medical Council of India (MCI) and has a license to practice allopathic medicine. The official definition of an RMP is a village doctor who practices modern (allopathic) medicines without any formal registration/ approval or legal sanction. ${ }^{1}$

We from the medical world call them Rural Medical Practitioners (even if they are practicing in an urban area). What exactly is this RMP's qualification? Has he undergone some course of study with a qualifying exam? Is he certified by a University or Board of Education? Then how come the society has accepted him as part of the medical world? What actually is his role? He practices medicine. What kind of medicine? Allopathy, Ayurveda or Homeopathy? He gives injections and even starts intravenous infusions in people's homes. Does he know the possible complications or side effects of the drugs or procedures that he is dealing with? Do we as a society allow a completely unqualified person to diagnose diseases and administer drugs and injections? Who gives them these sanctions and why are people soliciting them? What does the MCI and other professional bodies have

Financial or Other, Competing Interest: None.

Submission 26-07-2017, Peer Review 01-09-2017,

Acceptance 08-09-2017, Published 14-09-2017.

Corresponding Author:

Nallapu Samson Sanjeeva Rao,

Professor,

Department of Community Medicine,

NRI Medical College, Chinakakani,

Mangalagiri Mandal,

Guntur District, Andhra Pradesh.

E-mail: samson.nallapu@yahoo.com

DOI: $10.14260 /$ jemds $/ 2017 / 1154$ to say about the RMP? Do we allow an unskilled cement worker to design and build our home?

\section{The Roots}

It is now well accepted that the state is unable to bring quality health care within the reach of the people, especially those living in rural areas. This has however led to the emergence of a new tier of "physicians," running a parallel heath care system and playing a formidable role in the rural health care market as rural health providers. This group of self-styled practitioners called RMPs, despite their lack of knowledge, skills and qualification are doing good business in the villages taking advantage of the lacunae in the public health care system. As testimony to their legitimacy, they manage certificates from unauthorised and unrecognised institutions. ${ }^{2}$ A survey conducted by members of the Indian Medical Association (IMA) and the Andhra Pradesh Private Hospitals and Nursing Homes Association (APNA) in Hyderabad city, found at least 400 unqualified medical practitioners operating in three areas alone. ${ }^{3}$

An RMP is usually one who has had some experience of heath care activity by working as assistant to a physician for varying amounts of time. His educational level may be anything from high school to graduation (BA, etc.). At some point, he decides that he has learnt enough and strikes out on his own and sets up a shop in a convenient village. One reason he flourishes is that there is no qualified doctor in or near that village. The Govt. health sub-centre is largely deserted and the PHC is situated too far and is anyway closed in the afternoons. One common excuse given is that, as there is no qualified doctor people have no choice but to use the services of these itinerant quacks. We must keep in mind that there are others in the village like the ANM, the ASHA and other workers who have received proper training in basic health care at the village level. 


\section{The Physician and RMP Pact}

Earlier this RMP used to go around on a bicycle with his box of medicaments and treat people in their homes both in rural areas and also urban slums. They did whatever limited practice that they were aware of and people paid them with whatever they could. Today the role of the RMP has widened and has become more lucrative attracting even unemployed graduates to take up this activity. More importantly he has become the tout of sorts for city or town based doctors and specialists. The name given to this sordid business is "RMP practice." The private hospitals and doctors organise and finance periodic "training camps" for the RMPs at the block level supposedly to teach them basic medical care, but the real intention is to establish referral mechanisms with appropriate financial incentives. ${ }^{4}$ The private hospitals and doctors are utilising the services of RMPs for promoting their business interests. In the process, the qualified doctors are actually providing legitimacy to the RMPs.

A doctor setting up a clinic will meet the RMPs in the surrounding villages and will advise them to bring their patients to him. Why would the RMP do that without some compensation? So a deal is made that a percentage of the fees realised by the clinic will be given to the RMP. The percentage may range from $20 \%$ to $35 \%$ of the fees collected. Naturally, the more the patient is made to pay, the more the kickbacks. To cite an example, an RMP will motivate a peri-menopausal woman with irregular periods to get a Hysterectomy done and bring her to the city hospital. The doctor's knowledge and experience, which helps him to diagnose and decide whether the woman really needs the hysterectomy is immaterial. He just has to put his conscience aside and do the surgery and give a percentage of the fees to the RMP. The highly qualified doctors are prostituting their skills at the behest of their pimp, i.e. the RMP. We hear of doctors giving parties to their RMPs and gifting them in addition to money, stethoscopes and BP apparatuses. Doctors are not only accepting them as equals in the medical practice, but are also following the RMP's treatment advice. This unholy tryst between the urban doctor and the RMP in fleecing patients by doing unnecessary surgeries, procedures, expensive lab tests, etc. is bringing a terrible reputation to the noble profession of medicine. RMPs sometimes do negative campaigns against qualified doctors. It is alleged that RMPs refuse to treat the villagers in emergency if they go to qualified doctors, who have no referral arrangements with them. The nexus has adverse impact on the quality of private medical care, which results in unnecessary tests, surgeries and treatments. ${ }^{4}$

\section{Nexus between Pharmaceutical Companies and Quacks}

Numerous small pharmaceutical companies support quacks, because they are an inexpensive marketing source to clueless patients. Most villages in India are still without a doctor or proper healthcare facilities. Quacks are giving costly medications to patients in an attempt to realise big margins and gifts from pharmaceutical companies, as they are not committed by oath to safely manage patients. Reckless prescription of drugs, even antibiotics will add to the impending antibiotic disaster even in remote villages. ${ }^{5}$

\section{Mainstreaming Efforts}

Attempts have been made by well-meaning Governmental authorities to give some training to these RMPs and certifying them. The Government of India (GOI) has advocated their involvement in the implementation of the national health and family welfare programmes in the country. Some pilot studies have shown that the RMPs are interested in getting involved in the national health and family welfare programmes. It is advocated that they can be involved in the delivery of MCH and family planning services. ${ }^{6}$

These RMPs have also formed their own unions and are clamouring for recognition of some sort to allow them to continue their practices. On one hand we lament the poor quality of our MBBS graduates who are being trained for five and a half years (1 year of internship). On the other hand, we want to give some hotchpotch training to these quacks that do not even have basic qualification and allow them to play with people's lives, both health wise and financially.

\section{The Solution}

The erstwhile Primary Health Centre and Sub-Centre, which was useful earlier is now no longer relevant to the health needs (both perceived and real) of people living in rural areas. The lofty concept of PHC has finally dwindled into basic health care on an outpatient basis for simple diseases with an onus on National Health Programmes, etc. However, the health problems of today's world, especially in the obscured division between rural and urban lifestyles is more complex and requires primary health care of a higher level. People now desire better and more modern scientific technology to deal with their health, just as in all other aspects of daily life.

Dharmaraj D et al upon interviewing village heads and the community found that the reasons why they seek the services of RMPs are easy accessibility, familiarity to villagers, availability round the clock and affordable services. ${ }^{7}$ There is a need for establishing hospitals in rural areas with full time qualified personnel like doctors, specialists, nurses, technicians and orderlies. These hospitals must be equipped to take on deliveries, surgeries and emergencies. If the Government cannot provide this, private parties may be allowed to set up these hospitals with standards for monitoring set by the Government. Upgrading some PHCs to CHCs is a move towards this, but the essential spirit of a hospital is lacking and they are still working as glorified PHCs.

Qualified doctors and specialists must stop encouraging the RMP and avoid sullying the reputation of the medical profession. Empathy for the patient and his family must play a role in diagnosis and management and not financial gains. If doctors are not sensitised to this essential prerequisite of their profession, then perhaps their training and apprenticeship must come under scrutiny. The so called "RMP practice" must be severely reproached by all.

If these RMP's must be mainstreamed in some way, limitations must be set upon them regarding use of injectable drugs, invasive procedures, etc. Emphasis must be on first aid, basic health care and prompt and appropriate referral.

A better alternative is to educate people and empower them to promote their own health and prevent disease by following healthy lifestyles. The common man must have sufficient knowledge to manage simple ailments with tried and tested home remedies or simple medications. They must also be directed on when and whom to approach for proper cost effective medical care. 


\section{REFERENCES}

[1] Kanjilal B. Quality of underground health care: a case study of Indian RMPs. Indian Institute of Health Management Research 2011.

http://ps4h.org/docs_iheapdf/1B_Kanjilal.pdf.

[2] Datta R. The world of quacks: a parallel health care system in rural West Bengal. IOSR Journal of Humanities and Social Science 2013;14(2):44-53.

[3] The menace of fake / quack doctors. Campaign against malpractices in health care areas Andhra has 1.5 lakh quack doctors: Report TNN 2003. http://charaka.hpage.co.in/quacksfakes_30685703.html.

[4] Narayana KV. The unqualified medical practitioners, methods of practice and nexus with the qualified doctors, working paper no: 70, 2006. Centre for economic and social studies Begumpet, Hyderabad http://www.cess.ac.in/cesshome/wp\%5Cwp-70.pdf.
[5] Lawrence K. Quacks in India claim majority 2015. http://www.medicalisland.net/featured/quacks-inIndia-claim-majority.

[6] Rao PH. Profile and practice of private medical practitioner in rural India. Health and Population Perspectives and issues 2005;28(1):40-9.

[7] Dharmaraj D, Duttagupta KK. Perspectives of the community and PHC doctors from three southern states in India on community preference for health services provided by rural medical practitioners. Indian Medical Gazette 2013:49-53. 